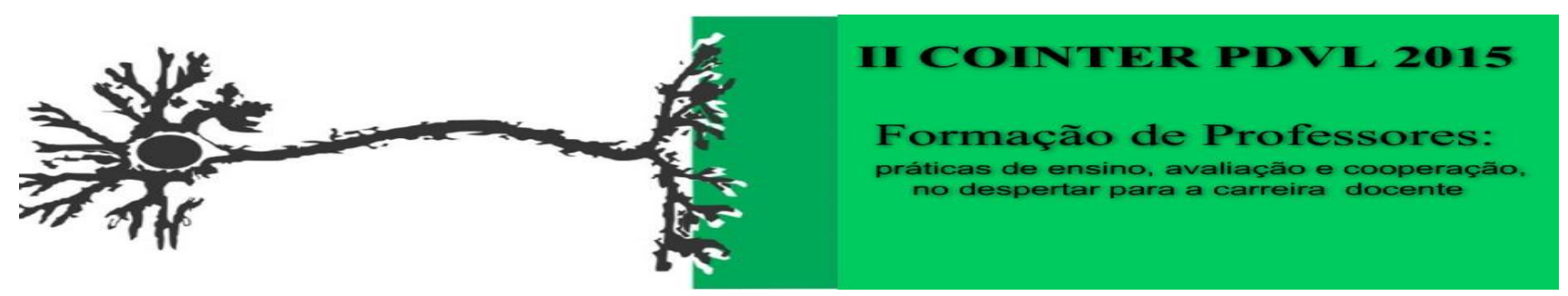

\title{
IMPORTÂNCIA DA ATUAÇÃO DO ALUNO INTEGRANTE DO PROGRAMA DE EDUCAÇÃO TUTORIAL NO CICLO DE PALESTRAS
}

\author{
Apresentação: Relato de Experiência \\ Marconi dos Santos Ribeiro Junior ${ }^{1}$; Carlindo Maxshweel Querino da Silva²; Isabele da Silva \\ Francelino $^{3}$; Jailson Machado Ferreira ${ }^{4}$
}

\section{Introdução}

O Programa de Educação Tutorial - PET, criado em 1979, objetiva a formação acadêmica de seus integrantes por meio de atividades relacionadas à Tríade - Ensino, Pesquisa e Extensão com intuito de agregar valores sociais e estimular a melhoria dos cursos de graduação.

Dentre suas atividades, o grupo PET Química, vinculado ao Curso de Licenciatura em Química do Instituto Federal de Educação, Ciência e Tecnologia da Paraíba campus João Pessoa realiza, anualmente, o Ciclo de Palestras. Esta atividade vinculada ao Ensino propõe a contribuição significativa de seus participantes por meio de discussões relacionadas ao contexto sociocultural em que estão envolvidos, buscando obter uma nova perspectiva do conhecimento, assumindo-se uma posição crítica perante o que foi discutido.

Diante disto, este relato apresenta a contribuição para a formação docente dos bolsistas do programa, adquirida na organização e execução do Ciclo de Palestras, realizado no lócus supracitado.

\section{Relato de Experiência}

No que concerne à organização do Ciclo de Palestras, o grupo se reúne para definir os temas e discutir sobre técnicas de elaboração e execução. A seletividade dos temas dá-se por meio de escolhas pessoais, ressaltando a relevância de temas inseridos no cotidiano, dificilmente abordados na graduação, manipulando sua linguagem com intuito de tornar acessível o conhecimento científico a qualquer cidadão. De acordo com o tema escolhido, o palestrante utiliza recursos metodológicos adequados à sua necessidade, a fim de favorecer a exposição de idéias, tendo o

\footnotetext{
${ }^{1}$ Licenciatura em Química, IFPB, marconijunior1@hotmail.com

${ }^{2}$ Licenciatura em Química, IFPB, maxshweel@gmail.com

${ }^{3}$ Licenciatura em Química, IFPB, isabelefrancelino@hotmail.com

${ }^{4}$ Professor Doutor, IFPB, jailsonmf@yahoo.com.br
} 
limite de 45 minutos cada. Em seu término, realiza-se uma discussão com o propósito de esclarecer possíveis dúvidas existentes dentre os participantes.

Dentre os temas, a associação de fenômenos com o cotidiano e de aspectos ambientais são essenciais às atividades do grupo. Por meio da análise dos discursos dos alunos presentes, percebese que os mesmos compreendem os conceitos apresentados, agregando significância às ações diárias, verificando sua importância, promovendo assim, a "construção de uma visão do mundo mais articulada e menos fragmentada, contribuindo para que o indivíduo se veja como participante de um mundo em constante transformação" (BRASIL, 1999, p.241).

A atuação dos bolsistas na atividade está diretamente relacionada à associação da teoria aprendida no âmbito escolar e a vivência prática correlacionada à sala de aula. Considerando que formação docente não se dá por meio apenas da experiência prática, Pimenta (2005, p. 26) afirma que o saber docente também formado por teorias da educação, esclarecendo seu importante papel.

[...]Os saberes teóricos propositivos se articulam, pois, aos saberes da prática, ao mesmo tempo ressignificando-os e sendo por eles ressignificados. O papel da teoria é oferecer aos professores perspectivas de análises para compreender os contextos históricos, sociais, culturais, organizacionais, e de si mesmos como profissionais, nos quais se dá sua atividade docente, para neles intervir, transformando-os. Daí é fundamental o permanente exercício da crítica das condições materiais nas quais o ensino ocorre.

Uma melhoria na qualidade da formação do aluno pertencente ao PET é a agregação de valores pedagógicos, capazes de formular novas estratégias de ensino que sejam mais dinâmicas e atrativas à comunidade discente.

\section{Considerações}

Verifica-se que o empenho e desempenho dos alunos envolvidos no Ciclo de Palestras, evidencia a constante busca pela excelência na prática docente, abrindo mão de métodos estáticos, facilitando a troca de informações por meio do diálogo e fortalecendo o papel do professor enquanto educador consciente. Assim como, as atividades desenvolvidas no âmbito do Programa de Educação Tutorial coadunam conhecimentos teóricos construídos na sala de aula e os potencializa, por meio da prática, favorecendo o crescimento profissional do professor em seus primeiros passos.

\section{Referências}

BRASIL. Ministério da Educação (MEC), Secretaria de Educação Média e Tecnológica (Semtec). Paramêtros Curriculares Nacionais para o Ensino Médio. Brasília: MEC/Semtec, 1999.

PIMENTA, Selma Garrido, GHEDIN, Evandro (Orgs.). Professor reflexivo no Brasil: gênese e crítica de um conceito. 3. ed. São Paulo: Cortez, 2005. 